\title{
Comparison of remifentanil concentrations with and without dexmedetomidine for the prevention of emergence cough after nasal surgery: a randomized double-blinded trial
}

Ha Yeon Kim', Hyun Jeong Kwak², Dongchul Lee ${ }^{2}$, Ji Hyea Lee', Sang Kee Min and Jong Yeop Kim ${ }^{1 *}$ (1)

\begin{abstract}
Background: Preventing emergence cough after nasal surgery is critical. Emergence cough can provoke immediate postoperative bleeding, which leads to upper airway obstruction. In the present study, we compared the effect-site concentration (Ce) of remifentanil to prevent emergence cough after propofol anesthesia for nasal surgery when remifentanil was or was not combined with dexmedetomidine.

Methods: Forty-seven patients with propofol-remifentanil anesthesia for nasal surgery were randomly assigned to a dexmedetomidine group (Group D, $n=23$ ) or a saline group (Group $S, n=24)$. Group D and Group $S$ were infused with dexmedetomidine $(0.5 \mu \mathrm{g} / \mathrm{kg})$ and saline, respectively, for $10 \mathrm{~min}$ before the completion of surgery. A predetermined Ce of remifentanil was infused until extubation. Remifentanil Ce to prevent cough in 50 and $95 \%$ of patients ( $\mathrm{EC}_{50}$ and $\mathrm{EC}_{95}$ ) was estimated using modified Dixon's up-and-down method and isotonic regression. Hemodynamic and recovery parameters were recorded.

Results: The $\mathrm{EC}_{50}$ of remifentanil Ce was significantly lower in Group D than in Group S $(2.15 \pm 0.40 \mathrm{ng} / \mathrm{mL}$ vs. $2.66 \pm 0.36 \mathrm{ng} / \mathrm{mL}, p=0.023)$. The $\mathrm{EC}_{95}(95 \% \mathrm{Cl})$ of remifentanil Ce was also significantly lower in Group D [2.75 $(2.67-2.78) \mathrm{ng} / \mathrm{mL}$ ] than in Group S [3.16 (3.06-3.18) ng/mL]. Emergence and recovery variables did not differ between the two groups.

Conclusion: The remifentanil $\mathrm{EC}_{50}$ to prevent cough after propofol-remifentanil anesthesia was significantly lower (approximately 19\%) when a combination of remifentanil and $0.5 \mathrm{\mu g} / \mathrm{kg}$ dexmedetomidine was used than when remifentanil infusion alone was used in patients undergoing nasal surgery. Therefore, the Ce of remifentanil may be adjusted to prevent emergence cough when used in combination with dexmedetomidine.
\end{abstract}

Trial registration: ClinicalTrials.gov (NCT03622502, August 9, 2018).

Keywords: Cough, Dexmedetomidine, Emergence, Remifentanil

\footnotetext{
* Correspondence: kjyeop@ajou.ac.kr

'Department of Anesthesiology and Pain Medicine, Ajou University School of Medicine, 164, World cup-ro, Yeongtong-gu, Suwon 16499, South Korea

Full list of author information is available at the end of the article
}

(c) The Author(s). 2021 Open Access This article is licensed under a Creative Commons Attribution 4.0 International License, which permits use, sharing, adaptation, distribution and reproduction in any medium or format, as long as you give appropriate credit to the original author(s) and the source, provide a link to the Creative Commons licence, and indicate if changes were made. The images or other third party material in this article are included in the article's Creative Commons licence, unless indicated otherwise in a credit line to the material. If material is not included in the article's Creative Commons licence and your intended use is not permitted by statutory regulation or exceeds the permitted use, you will need to obtain permission directly from the copyright holder. To view a copy of this licence, visit http://creativecommons.org/licenses/by/4.0/. The Creative Commons Public Domain Dedication waiver (http://creativecommons.org/publicdomain/zero/1.0/) applies to the data made available in this article, unless otherwise stated in a credit line to the data. 


\section{Background}

Emergence cough after general anesthesia leads to serious adverse effects including surgical site bleeding, wound disruption, hemodynamic instability, and increased intracranial and intraocular pressure [1]. The prevention of cough in nasal surgery patients is especially important because cough can provoke immediate postoperative bleeding, which leads to upper airway obstruction [2].

Remifentanil has emerged as a medication for cough prevention after general anesthesia. In prior studies, effective remifentanil effect-site concentrations (Ce) under various conditions have ranged from 1.5 to $2.9 \mu \mathrm{g} / \mathrm{mL}$ [3-6]. Although an increasing dose of remifentanil may effectively prevent cough, this drug also increases the incidences of adverse effects including respiratory depression, nausea and vomiting, or delayed emergence $[3,7]$. Thus, to decrease remifentanil's $\mathrm{Ce}$ and its side effects when administered alone, co-administration of other adjuvant drugs may prove useful.

Dexmedetomidine is a strong affinity for the $\alpha_{2}$-adrenoreceptor and reduces the use of sedatives and analgesics, though it has little effect on respiratory depression even when used at maximum concentrations [8]. Combination of dexmedetomidine and a low-dose remifentanil administered prior to the end of surgery is reportedly effective in preventing emergence cough without respiratory depression compared to a low-dose of remifentanil alone [9]. In addition, co-administration of dexmedetomidine $(0.5 \mu \mathrm{g} / \mathrm{kg})$ with low-dose remifentanil was not inferior to a high dose of remifentanil alone for preventing emergence cough [10]. However, the effective remifentanil Ce to prevent emergence cough when administered with a single dose of dexmedetomidine has not been evaluated.

The present study estimated the effective remifentanil Ce to prevent emergence cough in 50 and $95 \%$ of patients $\left(\mathrm{EC}_{50}\right.$ and $\left.\mathrm{EC}_{95}\right)$ administered remifentanil and dexmedetomidine $(0.5 \mu \mathrm{g} / \mathrm{kg})$ and remifentanil alone after propofol anesthesia for nasal surgery.

\section{Methods}

The present prospective trial was conducted with the approval of our Institutional Review Board (AJIRB-MEDOBS-18-170) and registered at ClinicalTrials.gov (ref no.: NCT03622502). After obtaining written informed consent from all participants, patients with American Society of Anesthesiologists physical status I or II, aged between 19 and 65 years, who had planned septoplasty or endoscopic sinus surgeries were enrolled. Participant exclusion criteria were a potentially difficult airway (Mallampati class 3 or 4), use of angiotensin converting enzyme-inhibitors, obesity with body mass index $>35 \mathrm{~kg} / \mathrm{m}^{2}$, current smoker, a recent upper airway infection, asthma, and uncontrolled hypertension. According to a randomization generator (http://www.random.org), patients were randomized to a dexmedetomidine group (Group D) or a saline group (Group S).

When the patient arrived at the operating room, anesthetic monitoring including non-invasive blood pressure (BP) measurement, electrocardiography, and peripheral pulse oximetry was started. The anesthetic depth was assessed by attaching a bispectral index (BIS) sensor to the participant's forehead. For anesthesia induction, target-controlled infusion was started (Ce of propofol at $5.0 \mu \mathrm{g} / \mathrm{mL}$ and $\mathrm{Ce}$ of remifentanil $\mathrm{Ce}$ at 4.0 $\mathrm{ng} / \mathrm{mL}$ ) using an infusion device (Orchestra, Fresenius Vial, France). Two minutes after rocuronium $(0.6 \mathrm{mg} / \mathrm{kg})$ injection, endotracheal intubation was performed using a $7.0 \mathrm{~mm}$ and $7.5 \mathrm{~mm}$ cuffed tube in men and women, respectively, with a cuff pressure of $20-25 \mathrm{mmHg}$.

Anesthesia was maintained with Ce of propofol at 2.0$3.0 \mu \mathrm{g} / \mathrm{mL}$ and $\mathrm{Ce}$ of remifentanil at $3.0-5.0 \mathrm{ng} / \mathrm{mL}$. Anesthetic depth was adjusted from a BIS value of 40 to 60. Fluctuations of intraoperative heart rate (HR) and BP were adjusted to within $20 \%$ of the baseline (before the induction of anesthesia). When HR dropped below 45 $\mathrm{bpm}$, atropine $(0.5 \mathrm{mg})$ was administered. When the mean BP decreased to less than $20 \%$ of the baseline, ephedrine $(6 \mathrm{mg})$ was administered.

Dexmedetomidine $(0.5 \mu \mathrm{g} / \mathrm{kg})$ in Group $\mathrm{D}$ and the same volume of normal saline in Group $S$ were infused using a syringe pump for over $10 \mathrm{~min}$, before completion of surgery. Upon completion of surgery, propofol infusion was halted. Throughout emergence, remifentanil infusion of predetermined Ce was continued for more than 15 min until extubation. Drugs were administered by one researcher (JY Kim) according to the patient's group identity (dexmedetomidine or normal saline and a pre-determined Ce of remifentanil). Patients' degree of muscle relaxation was estimated using train-of-four (TOF) monitoring. When the TOF ratio was more than $90 \%$, neostigmine $(0.02 \mathrm{mg} / \mathrm{kg})$ and glycopyrrolate $(0.004 \mathrm{mg} / \mathrm{kg})$ were injected. Subsequently, assisted ventilation with $100 \%$ of inspired oxygen was initiated in response to spontaneous patient breathing. When the patient showed spontaneous eyes opening or response to a verbal command, we confirmed that their spontaneous breathing was sufficient and removed their endotracheal tube. Thereafter, remifentanil was stopped and a facial mask delivering 100\% oxygen was applied. The patient was moved to a post-anesthetic care unit (PACU) after confirming the adequacy of their consciousness and respiration over a 5 -min period. In the PACU, the patient was assessed for postoperative nausea and vomiting (PONV). Postoperative pain was quantified using a numeric rating scale (NRS), ranging from 0 to $10(0=$ no pain, $10=$ worst possible pain). If the patient suffered from pain rated worse than a 5 or requested painkiller administration, fentanyl $(50 \mu \mathrm{g})$ was injected. Sedation 
was also evaluated using a modified Wilson sedation scale [11]. When the modified Aldrete score was $\geq 9$, patients were moved to the ward [12].

Patients were sequentially enrolled using a Dixon's upand-down allocation approach, as previously [13]. Patient enrollment continued until both groups reached at least 20 patients and six success-failure pairs. Cough was defined as a sudden expulsion of air with abdominal muscle contraction and classified into one of the four grades (grade $0=$ no cough, grade $1=$ single cough, grade $2=$ more than one episode of non-sustained cough, grade 3 =sustained and repetitive cough). Cough was assessed between the end of surgery and $5 \mathrm{~min}$ after extubation. The $\mathrm{Ce}$ of remifentanil was initiated with $2.0 \mathrm{ng} / \mathrm{mL}$ in each group. The Ce of remifentanil of the next patient was determined by the presence of coughing in the previous patient. If the patient had no cough or a single cough (grade 0 or 1 ), we defined this as successful prevention of cough, and the pre-determined Ce of remifentanil for the next patient was lowered by 0.4 $\mathrm{ng} / \mathrm{mL}$. If cough was not prevented successfully (grade 2 or 3), we determined the result to be a failure at preventing cough, and the pre-determined Ce of remifentanil for the next patient was increased by $0.4 \mathrm{ng} / \mathrm{mL}$.

During the operations, data on the Ce for propofol and remifentanil, mean $\mathrm{BP}, \mathrm{HR}$, pulse oximetry saturation $\left(\mathrm{SpO}_{2}\right), \mathrm{BIS}$ value, respiratory rate, and end-tidal $\mathrm{CO}_{2}$ $\left(\mathrm{EtCO}_{2}\right)$ were collected at seven time points, namely, baseline (T0), immediately before (T1) and after (T2) the start of dexmedetomidine or saline infusion, upon operation completion (T3), at eye opening (T4), and immediately (T5) and 5 min (T6) after extubation. The intraoperative use of medications to control BP or HR was also recorded.

Cough was assessed by one researcher (HY Kim) who was blinded to patients' group allocations and the predetermined Ce of remifentanil. The times elapsed between stopping propofol administration to eye opening (time to eye opening) and from stopping propofol administration to extubation (time to extubation) were recorded. For $5 \mathrm{~min}$ after extubation, hypoventilation (respiratory rate $<8$ breaths $/ \mathrm{min}$ ), laryngospasm, and desaturation $\left(\mathrm{SpO}_{2}<95 \%\right)$ were recorded. In the PACU, respiratory rate, PONV, pain scores using the NRS, Aldrete scores, sedation scale scores, and stay duration were recorded.

\section{Statistical analyses}

The $\mathrm{EC}_{50}$ and $\mathrm{EC}_{95}$ of remifentanil to prevent cough in Group D were the primary study outcomes. To obtain the $\mathrm{EC}_{50}$ by Dixon's method, minimum six success-failure pairs and 20 patients were needed [14]. The $\mathrm{EC}_{50}$ of remifentanil was obtained by the mean value of the mid-point for each failure-to-success pair. In a previous study on nasal surgery using Dixon's method, the standard deviation (SD) of $\mathrm{EC}_{50}$ of remifentanil Ce to prevent emergence cough was $0.38 \mathrm{ng} / \mathrm{mL}$ [4]. Since the step size of Ce should be larger than the previous SD, we set the change of the adjacent dose of remifentanil to $0.4 \mathrm{ng} / \mathrm{mL}$. To obtain the $\mathrm{EC}_{95}$ of remifentanil, the isotonic regression method using a pooled-adjacent-violators algorithm and a bootstrapping approach was also used, as previously [15]. No overlap between two $\mathrm{EC}_{95}$ values at $95 \%$ confidence interval (CI) was considered a significant difference [16].

Categorical variables were analyzed using the chisquared or Fisher's exact tests and presented as numbers (frequency). Continuous variables were analyzed using independent $\mathrm{t}$-tests or Mann-Whitney $\mathrm{U}$ tests and presented as means \pm SDs or medians (25th to 75th quartile). Measured variables were repeatedly analyzed using the linear mixed model. When the model revealed a significant interaction between group and time, a posthoc analysis was performed to identify time points which differed significantly. The variables were considered statistically significant when the $P$-value was less than 0.05 . Statistics were analyzed with SPSS (version 25.0, IBM Corporation, Armonk, NY, USA) and R (version 3.2.5).

\section{Results}

Forty-eight patients were enrolled between August 2018 and March 2019. One patient was withdrawn due to incorrect initiation of dexmedetomidine. Twenty-three patients in Group D and 24 patients in Group S included in this study (Fig. 1). Preoperative patients' characteristics and intraoperative details were comparable between the two groups (Table 1).

Success and failure rates to prevent emergence cough in consecutive patients are presented in Fig. 2. EC ${ }_{50}$ s were calculated by the Dixon's method from eight failuresuccess pairs in Group D and from seven failure-success pairs in Group S. The $\mathrm{EC}_{50}$ for remifentanil was significantly lower in Group D than in Group S $(2.15 \pm 0.04$ vs. $2.66 \pm 0.36 \mathrm{ng} / \mathrm{mL}$, respectively, $P=0.023)$. The $\mathrm{EC}_{95}(95 \%$ CI) for remifentanil was also significantly lower in Group D than in Group S [2.75 (2.67-2.78) vs. 3.16 (3.06-3.18) $\mathrm{ng} / \mathrm{mL}$, respectively], and their $95 \%$ CIs did not overlap.

During surgery, repeated measure variables including MBP, $\mathrm{HR}, \mathrm{SpO}_{2}$, BIS value, respiratory rate, and $\mathrm{EtCO}_{2}$ had similar trends over time in both groups (all $p$ values > 0.05) (data not shown). The number of patients who were administered ephedrine was comparable between the two groups [9 (39.1\%) in Group D vs. 11 (45.8\%) in Group S, $p=0.642]$. One patient in Group D received atropine.

During emergence, time to eye opening, time to extubation, and respiration rate were comparable between the two groups. Hypoventilation within 5 min of extubation occurred in six patients in Group D and in nine patients in Group $\mathrm{S}(P=0.401)$. This hypoventilation was transient in all patients and recovered with respiratory encouragement (Table 2). 


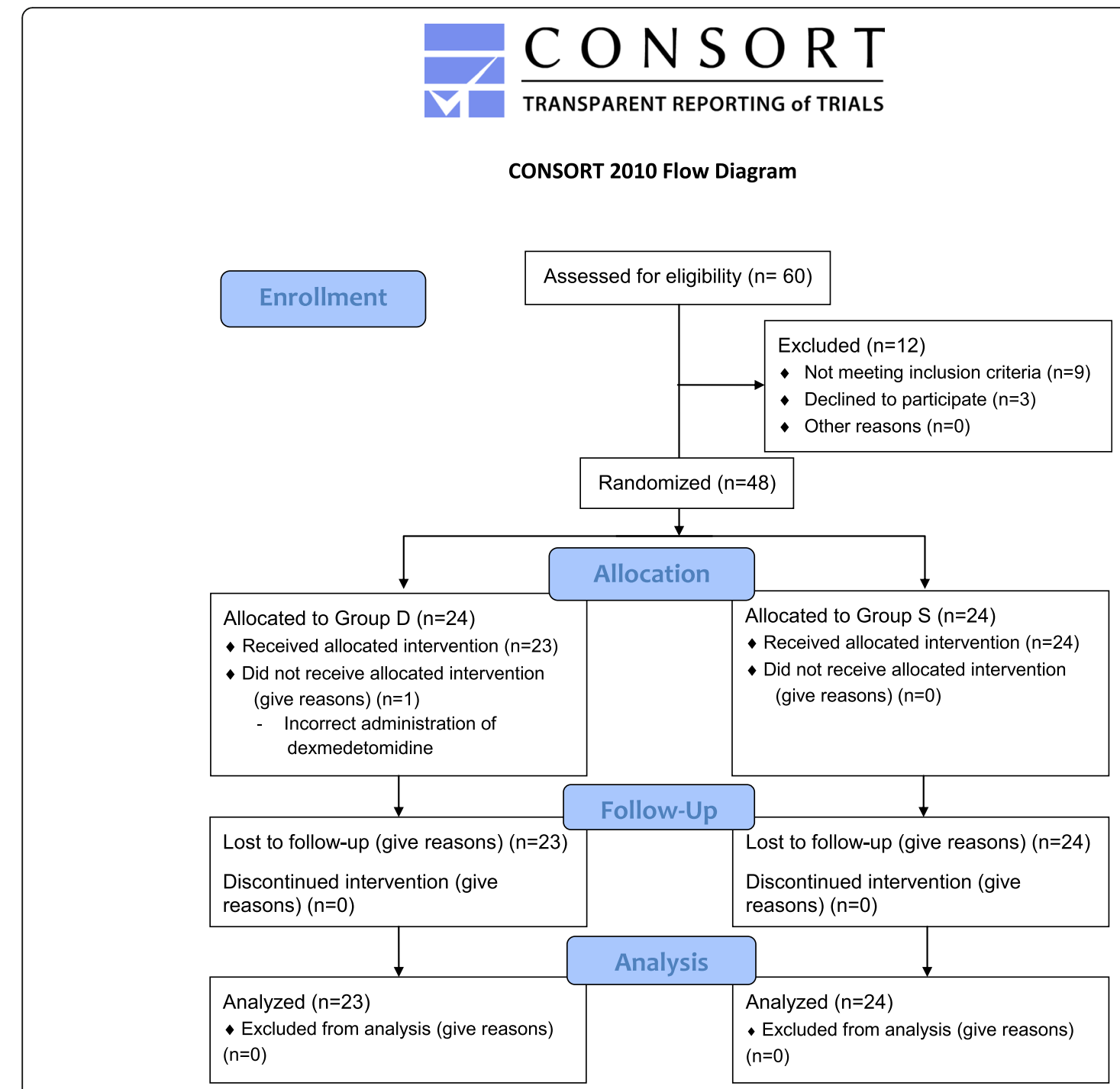

Fig. 1 The CONSORT flow diagram

Table 1 Preoperative and intraoperative patients' characteristics

\begin{tabular}{llll}
\hline & Group D $(\boldsymbol{n}=\mathbf{2 3})$ & Group S $(\boldsymbol{n}=\mathbf{2 4})$ & $\boldsymbol{P}$-value \\
\hline Sex, male n (\%) & $14(61)$ & $19(79)$ & 0.636 \\
Age, years & $40 \pm 12$ & $40 \pm 14$ & 0.875 \\
Weight, kg & $74(66-84)$ & $73(64-76)$ & 0.442 \\
Height, cm & $170(160-176)$ & $172(166-182)$ & 0.248 \\
ASA classification (I/II), n & $19 / 4$ & $18 / 6$ & 0.724 \\
Surgery time, min & $35(25-40)$ & $30(25-44)$ & 0.765 \\
Anesthesia time, min & $70(60-75)$ & $70(60-89)$ & 0.579 \\
\hline
\end{tabular}

Values are mean \pm standard deviation, median (25th - 75th quartile), or number (\%)

ASA American Society of anesthesiologist
In the PACU, NRS for postoperative pain, the patients' number receiving rescue analgesics, PONV, and stay duration were comparable between the two groups. Respiratory rate, Aldrete scores, and sedation scale scores also did not interact significantly with time and group (data not shown).

\section{Discussion}

In this study, we evaluated remifentanil's Ce to prevent emergence cough with and without co-administration of dexmedetomidine $(0.5 \mu \mathrm{g} / \mathrm{kg})$ after propofol anesthesia. The combined infusion of dexmedetomidine and remifentanil significantly reduced remifentanil $\mathrm{EC}_{50}$ and $\mathrm{EC}_{95}$ measures by 19 and 13\%, respectively, compared to remifentanil infusion alone. In addition, the combined use of these drugs did not delay the time to awakening or extubation and did not aggravate respiratory depression. 

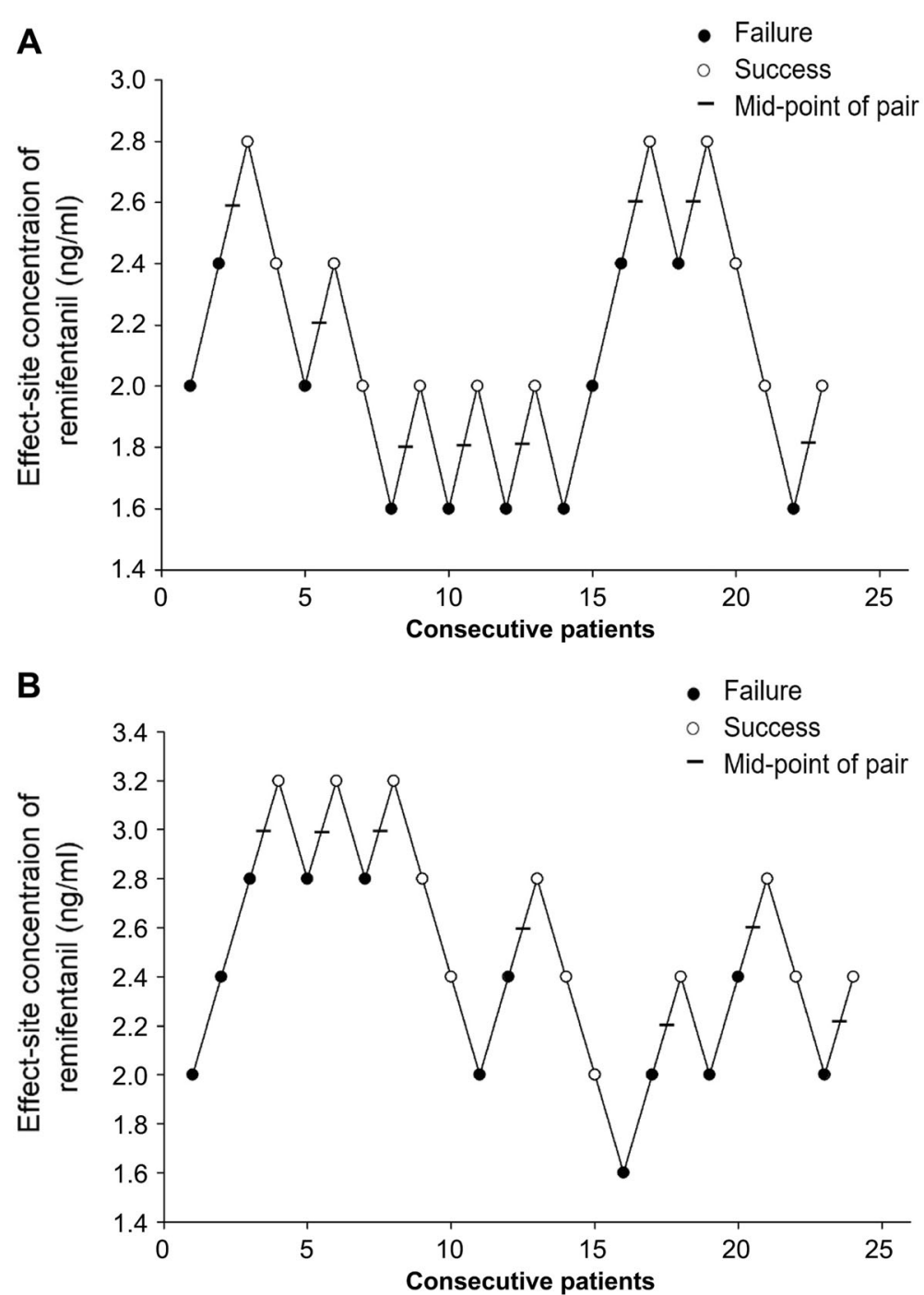

Fig. 2 Effect-site concentration of remifentanil by Dixon's method in Group D (a) and in Group S (b)

Cough is mediated by peripheral nerve terminals within the airway walls and by central vagus afferent nerves in the nodose ganglia or bodies of the jugular [17, 18]. Several antitussive agents are known to inhibit peripheral cough pathways (e.g., local anesthetics), central cough pathways (e.g., gamma-aminobutyric acid agonists), or both cough pathways (e.g., opioids) $[17,18]$. Of these, remifentanil is the antitussive agent of choice during surgery due to its uniquely rapid action without accumulation [7]. However, although remifentanil has a dose-dependent antitussive effect, it also has dosedependent adverse effects such as respiratory depression, nausea and vomiting, muscle rigidity, pruritus, or delayed emergence $[3,7]$.

In recent years, the application of dexmedetomidine, which has respiratory preserving properties, has grown during anesthesia [19]. Given this, several studies have assessed the effectiveness of dexmedetomidine to prevent cough [20-24]. At present, the results regarding the antitussive effects of dexmedetomidine have been controversial. Several studies have reported that dexmedetomidine may not prevent cough better than remifentanil, midazolam, or even saline [20-22]. However, other studies have reported that dexmedetomidine may prevent cough better than placebo (saline) $[23,24]$ and that it may have dose-dependent antitussive effects [23]. Pretreated dexmedetomidine $0.6 \mu \mathrm{g} / \mathrm{kg}$ bolus intravenous infusion over $10 \mathrm{~min}$ could reduce fentanyl-induced cough effectively without side effects in a previous study [25]. In addition, Lee et al. also found that the addition of a single dose of dexmedetomidine to a low-dose infusion of remifentanil during emergence from sevofluraneremifentanil anesthesia was effective in attenuating cough after thyroid surgery [9]. Although the criteria for 
Table 2 Emergence and recovery parameters

\begin{tabular}{|c|c|c|c|}
\hline & Group D $(n=23)$ & Group S $(n=24)$ & $P$-value \\
\hline \multicolumn{4}{|l|}{ During anesthetic emergence } \\
\hline Time to eye opening, sec & $560(490-670)$ & $565(453-714)$ & 0.975 \\
\hline Time to extubation, sec & $670(630-750)$ & $690(540-795)$ & 0.775 \\
\hline \multicolumn{4}{|l|}{ Respiration rate, breaths/min } \\
\hline Immediately after extubation & $10(9-12)$ & $12(9-13)$ & 0.412 \\
\hline 5 min after extubation & $12(12-13)$ & $12(10-13)$ & 0.360 \\
\hline Hypoventilation, n (\%) & $6(26)$ & $9(38)$ & 0.401 \\
\hline \multicolumn{4}{|l|}{ In the post-anesthesia care unit } \\
\hline Pain score, NRS & $2(2-3)$ & $2(2-3)$ & 0.644 \\
\hline Rescue analgesics, n (\%) & $2(10)$ & $2(9)$ & 0.456 \\
\hline PONV, n (\%) & $4(18)$ & $2(9)$ & 0.414 \\
\hline Stay duration, min & $30(30-40)$ & $30(30-40)$ & 0.745 \\
\hline
\end{tabular}

Values are median (25th - 75th quartile), or number (\%)

NRS Numeric rating scale $(0=$ none, $10=$ the worst), PONV Postoperative nausea and vomiting

enrolling patients and statistical methods in the Lee et al.'s study are different from those of our study, we also demonstrated that dexmedetomidine combined with remifentanil may be highly effective at preventing cough compared to remifentanil alone after nasal surgery.

According to the manufacturer, dexmedetomidine has a wide range of dosage in a bolus ( 0.5 to $2.0 \mu \mathrm{g} / \mathrm{kg}$ over $10 \mathrm{~min})$ and infusion ( 0.1 to $1.5 \mu \mathrm{g} / \mathrm{kg} / \mathrm{h})$ depending on the clinical situation, including general anesthesia, sedation in the intensive care unit, or procedural sedation. Although bradycardia and hypotension may occur with bolus doses [19], a bolus administration of dexmedetomidine is still considered as an attractive method because it is easy and simple. Since Guler's et al. presented a study that showed that administration of a single dose of dexmedetomidine $(0.5 \mu \mathrm{g} / \mathrm{kg})$ at the end of surgery reduces airway and circulatory reflexes during extubation [24], this administration method has become popular in clinical practices for smooth emergence [9, 10, 23, 26]. Hence, we set the administration dose of dexmedetomidine to $0.5 \mu \mathrm{g} / \mathrm{kg}$ in this study.

The present study revealed differences of $0.4-0.5 \mathrm{ng} /$ $\mathrm{mL}$ in remifentanil $\mathrm{EC}_{50}$ and $\mathrm{EC}_{95}$ between the two groups. In addition, a reduced Ce of remifentanil when dexmedetomidine was combined did not delay emergence time (from eye opening to extubation) compared to the use of remifentanil alone. In this study, the remifentanil $E_{95}$ after nasal surgery when remifentanil was used alone was $3.16 \mathrm{ng} / \mathrm{mL}$. This remifentanil Ce was a substantially higher dose than that reported previously in the context of thyroid surgery $(2.14 \mathrm{ng} / \mathrm{mL})$ or brain tumor surgery $(2.51 \mathrm{ng} / \mathrm{mL})[27,28]$. Meanwhile, Choi et al. [4] found that the ideal remifentanil EC 95 to prevent cough after nasal surgery was $2.94 \mathrm{ng} / \mathrm{mL}$, which is comparable to that reported in our study. Choi et al. suggested that coughing was more frequent after nasal surgery than after other types of surgery, potentially because of chronic inflammation in the nasal mucosa, perioperative mechanical irritation, and pharyngolaryngeal stimulation by blood. Thus, the type of surgery could be a factor determining the optimal remifentanil Ce to prevent emergence cough.

Despite our findings, the use of high concentrations of remifentanil (e.g., above $3.0 \mathrm{ng} / \mathrm{mL}$ ) to prevent cough may not be practical given that remifentanil infusion during emergence under propofol anesthesia may increase the hypnotic effects of propofol and respiratory depression [29]. In a previous study, remifentanil infusion at $3.0 \mathrm{ng} / \mathrm{mL}$ during laryngomicroscopic surgery after propofol anesthesia led to a higher incidence of hypoventilation and longer extubation time during emergence than remifentanil infusion at $2.6 \mathrm{ng} / \mathrm{mL}$ or less [6]. This result indicates that the combined use of dexmedetomidine and remifentanil for preventing emergence cough is feasible in clinical settings.

In this study, the combined use of remifentanil and dexmedetomidine did not attenuate hemodynamic changes during extubation better than remifentanil alone. This finding is contrary to previous reports in which hemodynamic changes were attenuated better with combined dexmedetomidine $(0.5 \mu \mathrm{g} / \mathrm{mL})$ and remifentanil $(1 \mathrm{ng} / \mathrm{mL})$ than with remifentanil infusion alone [9]. The mean Ce for remifentanil in the present study was 2.1 in Group D and $2.5 \mathrm{ng} / \mathrm{mL}$ in Group S. Remifentanil attenuated hemodynamic changes during emergence in a dose-dependent manner [5]. Thus, relatively high doses of remifentanil may have offset the cardiovascular effects of dexmedetomidine. Meanwhile, recovery 
profiles including respiratory rate were not different between the two groups, paralleling findings from a previous study [10]. The previous study suggested that remifentanil plays a major role in regulating respiratory profiles when combined with dexmedetomidine because it does not worsen the respiratory depression induced by remifentanil [10].

There were some limitations in the present study. First, although the Dixon' up-and-down method allows for good median estimation, it is a simple strategy. Because such median estimations depend on the chosen pairs (e.g., success-failure pairs or failure-success pairs) and clinical circumstances, the $\mathrm{EC}_{50}$ is a relative and not absolute value. Second, our sample size was estimated using the Dixon' up-and-down allocation approach and may be insufficient to confirm differences in secondary outcomes between the two groups. Third, all cases included in this study underwent propofol anesthesia. Since many hypnotic agents even at sub-hypnotic concentrations influence airway reflexes [30], a residual concentration of propofol at extubation can affect cough reflex. Therefore, different results may emerge in cases which utilize inhalational anesthesia. Lastly, we cannot completely rule out the negative recovery parameters and adverse effects resulting from the use of dexmedetomidine during the perioperative period. This study did not show that dexmedetomidine has a negative effect on the recovery of anesthesia. However, dexmedetomidine $(0.5 \mu \mathrm{g} / \mathrm{kg})$ combined with remifentanil $10 \mathrm{~min}$ before the end of surgery prolonged the time of extubation in an earlier study [9]. Because the included patients in this study were approximately 40 years old, this difference might be due to the age difference of included patients. Therefore, our results cannot be extrapolated to the elderly. In addition, when dexmedetomidine was coadministered with other sedatives or analgesics, the sedative or hemodynamic effects could be more pronounced [19]. Considering that dexmedetomidine has a long metabolic time, co-administration of dexmedetomidine and remifentanil should be used with caution in the elderly and co-morbid patients.

\section{Conclusions}

The Ce for remifentanil to prevent emergence cough after propofol anesthesia for nasal surgery was significantly lower when a single dose of dexmedetomidine $(0.5 \mu \mathrm{g} / \mathrm{kg})$ was co-infused with remifentanil than when remifentanil was administered alone. The Ce of remifentanil may be adjusted to prevent emergence cough when used in combination with dexmedetomidine.

\section{Abbreviations}

BIS: Bispectral index; BP: Blood pressure; Ce: Effect-site concentration; $\mathrm{Cl}$ : Confidence interval; $\mathrm{EC}_{50}$ : Effective concentration in $50 \%$ of patients; $\mathrm{EC}_{95}$ : Effective concentration in $95 \%$ of patients; $\mathrm{ETCO}_{2}$ : End-tidal $\mathrm{CO}_{\text {; }}$
HR: Heart rate; NRS: Numeric rating scale; PACU: Post-anesthesia care unit; PONV: Postoperative nausea and vomiting; SD: Standard deviations;

$\mathrm{SPO}_{2}$ : Pulse oximetry saturation; TOF: Train-of-four

\section{Acknowledgements}

Not applicable.

\section{Authors' contributions}

HYK: data collection, manuscript drafting and editing. HJK: study design, and interpretation. DL: formal analysis. JHL: data collection and analysis. SKM: data interpretation. JYK: study design, manuscript drafting and editing. All of the authors have read and approved the manuscript.

\section{Funding}

Not applicable.

Availability of data and materials

The datasets generated and analyzed during the present study are available from the corresponding author on reasonable request.

\section{Declarations}

\section{Ethics approval and consent to participate}

This study was approved by the Ethics Committee of the Ajou University Hospital Institutional Review Board (AJIRB-MED-OBS-18-170). Written informed consent was obtained from all subjects participating in the trial. The trial was registered prior to the first patient enrollment at ClinicalTrials. gov (ref no.: NCT03622502).

\section{Consent for publication}

All data published here are under the consent for publication. Written informed consent was obtained from all individual participants included in the study.

\section{Competing interests}

The authors declare that they have no conflict of interest.

\section{Author details}

${ }^{1}$ Department of Anesthesiology and Pain Medicine, Ajou University School of Medicine, 164, World cup-ro, Yeongtong-gu, Suwon 16499, South Korea. ${ }^{2}$ Department of Anesthesiology and Pain Medicine, Gachon University, Gil Medical Center, Incheon, South Korea.

Received: 8 September 2020 Accepted: 26 April 2021

Published online: 04 May 2021

\section{References}

1. Irwin RS. Complications of cough: ACCP evidence-based clinical practice guidelines. Chest. 2006;129(1 Suppl):54s-8s.

2. Halderman AA, Sindwani R, Woodard TD. Hemorrhagic complications of endoscopic sinus surgery. Otolaryngol Clin N Am. 2015;48(5):783-93.

3. Chang $\mathrm{CH}$, Lee JW, Choi JR, Shim YH. Effect-site concentration of remifentanil to prevent cough after laryngomicrosurgery. Laryngoscope. 2013;123(12):3105-9.

4. Choi EM, Park WK, Choi SH, Soh S, Lee JR. Smooth emergence in men undergoing nasal surgery: the effect site concentration of remifentanil for preventing cough after sevoflurane-balanced anaesthesia. Acta Anaesthesiol Scand. 2012:56(4):498-503.

5. Jun NH, Lee JW, Song JW, Koh JC, Park WS, Shim YH. Optimal effect-site concentration of remifentanil for preventing cough during emergence from sevoflurane-remifentanil anaesthesia. Anaesthesia. 2010;65(9):930-5.

6. Kim HY, Kim JY, Ahn SH, Lee SY, Park HY, Kwak HJ. Predicting effective remifentanil concentration in $95 \%$ of patients to prevent emergence cough after laryngomicroscopic surgery. Medicine (Baltimore). 2018;97(26):e11258.

7. Servin FS, Billard V. Remifentanil and other opioids. Handb Exp Pharmacol. 2008;182:283-311.

8. Hsu YW, Cortinez LI, Robertson KM, Keifer JC, Sum-Ping ST, Moretti EW, et al. Dexmedetomidine pharmacodynamics: part l: crossover comparison of the respiratory effects of dexmedetomidine and remifentanil in healthy volunteers. Anesthesiology. 2004;101(5):1066-76. 
9. Lee JS, Choi SH, Kang YR, Kim Y, Shim YH. Efficacy of a single dose of dexmedetomidine for cough suppression during anesthetic emergence: a randomized controlled trial. Can J Anaesth. 2015;62(4):392-8.

10. Kim JH, Ham SY, Kim DH, Chang CH, Lee JS. Efficacy of single-dose Dexmedetomidine combined with low-dose remifentanil infusion for cough suppression compared to high-dose remifentanil infusion: a randomized, controlled, Non-Inferiority Trial. Int J Med Sci. 2019;16(3):376-83.

11. Nemethy M, Paroli L, Williams-Russo PG, Blanck TJ. Assessing sedation with regional anesthesia: inter-rater agreement on a modified Wilson sedation scale. Anesth Analg. 2002:94(3):723-8.

12. Aldrete JA. The post-anesthesia recovery score revisited. J Clin Anesth. 1995; 7(1):89-91.

13. Dixon WJ. Staircase bioassay: the up-and-down method. Neurosci Biobehav Rev. 1991;15(1):47-50.

14. Pace NL, Stylianou MP. Advances in and limitations of up-and-down methodology: a precis of clinical use, study design, and dose estimation in anesthesia research. Anesthesiology. 2007;107(1):144-52.

15. Dilleen M, Heimann G, Hirsch I. Non-parametric estimators of a monotonic dose-response curve and bootstrap confidence intervals. Stat Med. 2003; 22(6):869-82.

16. Payton ME, Greenstone $\mathrm{MH}$, Schenker N. Overlapping confidence intervals or standard error intervals: what do they mean in terms of statistical significance? J Insect Sci (Online). 2003;3:34.

17. Canning BJ, Chang AB, Bolser DC, Smith JA, Mazzone SB, McGarvey L. Anatomy and neurophysiology of cough: CHEST guideline and expert panel report. Chest. 2014;146(6):1633-48.

18. Spina D, McFadzean I, Bertram FK, Page CP. Peripheral mechanisms II: the pharmacology of peripherally active antitussive drugs. Handb Exp Pharmacol. 2009;187:155-86.

19. Weerink MAS, Struys M, Hannivoort LN, Barends CRM, Absalom AR, Colin P. Clinical pharmacokinetics and pharmacodynamics of Dexmedetomidine. Clin Pharmacokinet. 2017;56(8):893-913.

20. Ryu JH, Lee SW, Lee JH, Lee EH, Do SH, Kim CS. Randomized double-blind study of remifentanil and dexmedetomidine for flexible bronchoscopy. Br J Anaesth. 2012;108(3):503-11.

21. Gao Y, Kang K, Liu H, Jia L, Tang R, Zhang X, et al. Effect of dexmedetomidine and midazolam for flexible fiberoptic bronchoscopy in intensive care unit patients: a retrospective study. Medicine. 2017; 96(25):e7090.

22. Kim SY, Kim JM, Lee JH, Song BM, Koo BN. Efficacy of intraoperative dexmedetomidine infusion on emergence agitation and quality of recovery after nasal surgery. Br J Anaesth. 2013;111(2):222-8.

23. Aouad MT, Zeeni C, Al Nawwar R, Siddik-Sayyid SM, Barakat HB, Elias S, et al. Dexmedetomidine for improved quality of emergence from general anesthesia: a dose-finding study. Anesth Analg. 2019;129(6):1504-11.

24. Guler G, Akin A, Tosun Z, Eskitascoglu E, Mizrak A, Boyaci A. Single-dose dexmedetomidine attenuates airway and circulatory reflexes during extubation. Acta Anaesthesiol Scand. 2005;49(8):1088-91.

25. Zhou W, Zhang D, Tian S, Yang Y, Xing Z, Ma R, et al. Optimal dose of pretreated-dexmedetomidine in fentanyl-induced cough suppression: a prospective randomized controlled trial. BMC Anesthesiol. 2019;19(1):89.

26. Kim SH, Oh YJ, Park BW, Sim J, Choi YS. Effects of single-dose dexmedetomidine on the quality of recovery after modified radical mastectomy: a randomised controlled trial. Minerva Anestesiol. 2013; 79(11):1248-58

27. Choi SH, Min KT, Lee JR, Choi KW, Han KH, Kim EH, et al. Determination of EC95 of remifentanil for smooth emergence from propofol anesthesia in patients undergoing transsphenoidal surgery. J Neurosurg Anesthesiol. 2015;27(2):160-6.

28. Lee B, Lee JR, Na S. Targeting smooth emergence: the effect site concentration of remifentanil for preventing cough during emergence during propofol-remifentanil anaesthesia for thyroid surgery. $\mathrm{Br} J$ Anaesth. 2009:102(6):775-8.

29. Bouillon TW, Bruhn J, Radulescu L, Andresen C, Shafer TJ, Cohane C, et al. Pharmacodynamic interaction between propofol and remifentani regarding hypnosis, tolerance of laryngoscopy, bispectral index, and electroencephalographic approximate entropy. Anesthesiology. 2004; 100(6):1353-72.
30. Sundman E, Witt H, Sandin R, Kuylenstierna R, Bodén K, Ekberg O, et al. Pharyngeal function and airway protection during subhypnotic concentrations of Propofol, isoflurane, and Sevoflurane: volunteers examined by pharyngeal Videoradiography and simultaneous Manometry. Anesthesiology. 2001;95(5):1125-32.

\section{Publisher's Note}

Springer Nature remains neutral with regard to jurisdictional claims in published maps and institutional affiliations.
Ready to submit your research? Choose BMC and benefit from:

- fast, convenient online submission

- thorough peer review by experienced researchers in your field

- rapid publication on acceptance

- support for research data, including large and complex data types

- gold Open Access which fosters wider collaboration and increased citations

- maximum visibility for your research: over $100 \mathrm{M}$ website views per year

At BMC, research is always in progress.

Learn more biomedcentral.com/submissions 